\title{
The Comparative Neurobehavioral Effects on Neuromuscular Coordination and Food Intake Following Long Term Beans Ingestion in Cd-1 Mice
}

\author{
Aduema $\mathbf{W}^{*}$ \\ Department of Human Physiology, Gregory University, Nigeria \\ Submission: December 01, 2017; Published: January 03, 2018 \\ *Corresponding author: Aduema W, Department of Human Physiology, Gregory University, Uturu, Abia State, Nigeria, Tel: 8038046678; \\ Email: Wadioniaduema@gmail.com
}

\begin{abstract}
Beans, the stable diet of Nigerians contains serotonin and its precursor, 5-Hydroxytryptophan. It was therefore the aim of this study to find out whether long term ingestion of beans diet has effects on neurobehavioral parameters using 40 Swiss white mice. The mice were randomly assigned into four groups, viz; A- control, B-cooked beans diet ( $50 \% \mathrm{w} / \mathrm{w}), \mathrm{C}-$ uncooked beans diet (50\% w/w), while another set of mice were placed on serotonin precursor (5-HTP) diet $(0.2 \mathrm{mg} / 50 \mathrm{~g} \mathrm{w} / \mathrm{w})$ (D) for thirty days. All the mice had access to clean drinking water ad libitum. Before the neurobehavioral parameters were assessed, the phytochemical analysis of the beans, LD50 of the beans and that of the serotonin precursor (5-HTP) was determined. Serotonin concentration was measured in beans using gas chromatography analysis. Motor coordination was investigated alongside food intake. Beam walking was used to assess motor coordination. The results showed that food intake was reduced in beans diet-fed mice (B and C) when compared to control ( $\mathrm{p}<0.01$ respectively).On the other hand, beans fed mice (B and C), showed better motor coordination when compared to control $(A)$. This is because the frequency of foot slip, distance covered was significantly higher ( $p<0.05$ ) compared to the control (A) while the latency of fall was longer compared to the control. Group (D) produced similar results observed in B and C. Thus suggesting that serotonin may be involved in the action in beans (B and C). In conclusion, long term ingestion of beans improves motor coordination bur reduce food intake.
\end{abstract}

Keywords: Beans; Beam walking; motor coordination; Mice

\section{Introduction}

The black-eye beans which is commonly called iron beans in Nigeria, is known for its prominent black spot along its side. This bean has been a popular food in the Southern US for hundreds of years. Sometimes, referred to as cowpeas, China pea, Cowgramin United State or Niebe in French speaking Africa [1-3]. Cowpea or black eye beans is well known for its good source of dietary protein for human consumption and for animal feed in the tropics, especially in Africa, Brazil and India. It thrives well in hotter more arid climates and more infertile soils than other food legume crops due to its symbolic nitrogen fixing abilities which helps in maintaining soil fertility in peasant cropping systems. Over $65 \%$ of the cowpea crop is produced in Africa; Nigeria and Niger producing $50 \%$ of the World supply. The United States is the only developed country producing large amount of cowpea [1].

The main centres of cultivation of cowpea in Nigeria are Kano, Katsina, Bauchi, Bornu, Sokoto and Niger State in the
North and Ibadan, Owo and Benin in the West [4]. Cowpea (black eye beans) contains other chemical compounds including saponins, tannins, glycosides, flavonoids etc. Among the array of chemical constituents, serotonin has neurobehavioral actions on mood, memory, learning, and motor coordination [5]. Therefore, since beans contain neurotransmitters and chemicals that can potentially affect behavioral patterns, it may be worthwhile to find out whether long-term ingestion of Nigerian beans can affect behavior. This was what motivated our interest when we consider the challenges that confront human behavior and how behavioral disorders still remains a global concern [6]. Furthermore, since black eye beans that constitutes a major portion of the Nigerian diet contains some neurotransmitters notably, serotonin and its precursor that have neurobehavioral actions, it is conceivable that the consumption of beans diet can affect our behavior, it is also possible that its effects on behavior may be beneficial in the management of behavioral disorders that are common in the world including Nigeria. Therefore 
this research on beans (Vigna unguiculata) is worthwhile for the public to know whether Nigeria beans will be beneficial or harmful in the listed neurobehavioral parameters, namely; motor coordination.

\section{Materials and Methods}

\section{Experimental animals/grouping}

Forty Swiss white mice of both sexes weighing between (18-30g) and bred at the animal room of the Department of Human Physiology, University of Nigeria, Nsukka, were used for this study after approval by the College Ethical Committee of Abia State University. The animals were transported to the animal house of Department of Physiology, Abia State University, Uturu, Nigeria, were they were acclimatized under standard laboratory conditions and given free access to normal feed and clean drinking tap water. The animals were randomly assigned into four groups, control and a test group. The animals in the control group received normal feed (rodent chow) only; while the test group received mixed feed of $50 \mathrm{~g}$ cooked and uncooked beans per every $50 \mathrm{~g}$ of rodent chow ( $50 \%$ of beans diet) for 30 days. This is sequel to the fact that the determined LD50 for intraperitoneal administration of beans was $937.04 \mathrm{mg} /$ $\mathrm{kg}$. Synthetic serotonin precursor(5-Hydroxytryptophan) was obtained from May and Baker (M\&B) limited, Enfield, Middle Sex, United Kingdom(UK), and used for the study. From the estimation of the powdered 5-Hydroxytryptophan (serotonin precursor) content of beans according to the method of Feldman and M-Lee [7] as modified by Mosienko et al. [8]. The serotonin precursor diet was prepared by mixing $20 \mathrm{mg}(0.04 \mathrm{~g})$ of the precursor in $100 \mathrm{~g}$ of the feed. One gram $(1 \mathrm{~g})$ of the mixture was mixed with $99 \mathrm{~g}$ of the feed. So that the amount of 5HTP added was equivalent to that contained in the beans diet? An electric blender was used to blend the mixture to form the serotonin precursor diet.

\section{Experimental Design}

Mice were weighed using digital weight balance. Identification of animals was simply done using identification cards attached to each cage, because animals were singly housed. The mice were grouped into four: Each of these groups consisted of ten (10) mice [group 1=control, group $2=$ cooked beans, group $3=$ uncooked beans and group 4=5HTP]. In all, forty (40) mice were used for the experiments and the experiments were run for thirty (30) days. The mice were aged between 30 and 35 days and weighed between $15 \mathrm{~g}$ and $30 \mathrm{~g}$. All the animals were clinically and andrologically examined and confirmed to be free from systemic disorders.

\section{Procedure}

The mice were carried to the test room in their home cages. The mouse was removed from its home cage and placed at one end of the balance beam. After the mouse has secured its grip on the beam, the trial begins. The maximum length of the trial is five minutes. The mouse is tested under white light, during the dark phase. The beam is cleaned with $70 \%$ ethanol and permitted to dry between each trial.

\section{What was measured?}

a) Distance travelled: The number of line crosses.

b) Foot Slips: Number of times one of the mouse's back feet slips from the beam

c) Number of turns: Frequency that the animal reversed direction

d) Latency to fall: Time at which the animal fell off of the beam. If a fall occurred the animal was not placed back on the beam but was returned to the home cage. The trial was not repeated.

\section{Statistical Analysis}

Data between the groups was analyzed by one-way analysis of variance (ANOVA) followed by Post-hoc using Newman-Keuls. Data were presented as Mean \pm SEM and a "P" value less than 0.05 , was considered statistically significant. Statistical analysis was done with the aid of computer software SPSS (Brain Series China) and Excel from Windows XP.

\section{Results}

\section{Beam Walking}

The frequency of foot slips of the different experimental groups was recorded as $7.20 \pm 0.88 ; 4.38 \pm 1.00 ; 4.38 \pm 1.12$ and $2.71 \pm 0.42 / 5 \mathrm{~min}$ for mice fed with control, cooked, uncooked beans and serotonin precursor diets respectively. The frequency of foot slips for the cooked and uncooked beans was significantly different from control at $\mathrm{p}<0.05$. However, the serotonin precursor fed mice was also significantly lower $(\mathrm{P}<0.01)$ compared to control (Figure 1).

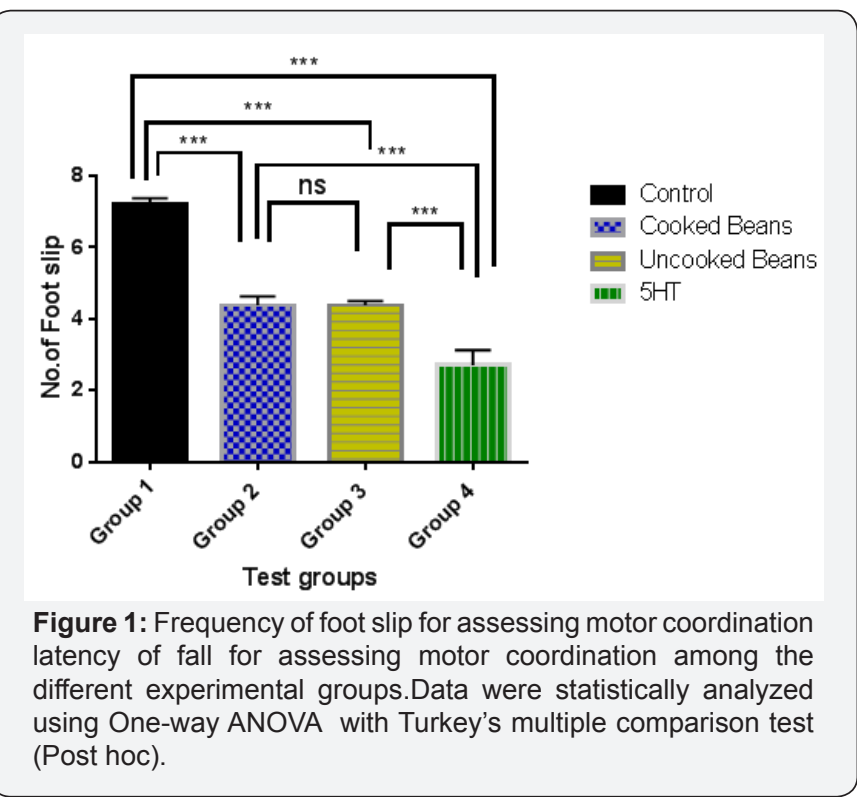




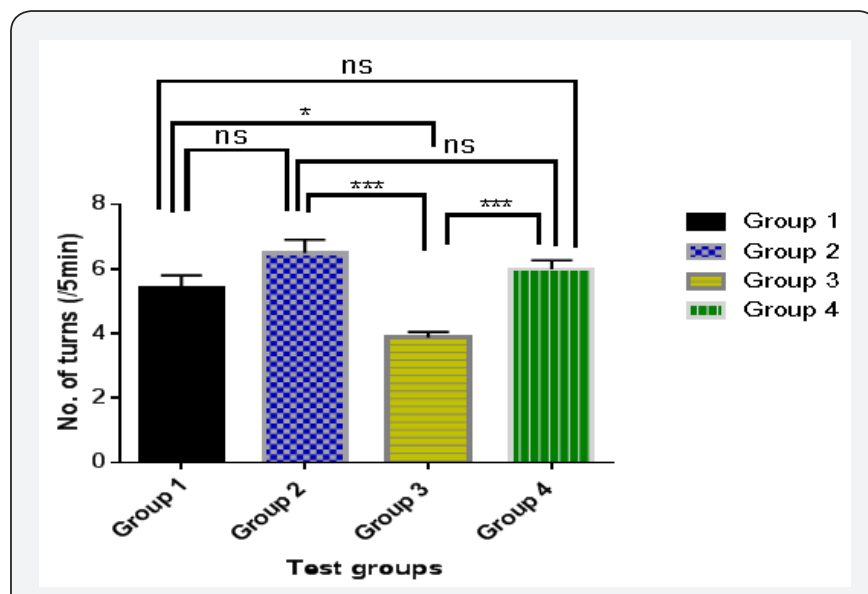

Figure 2: Number of turns for assessing motor coordination among the different experimental groups.Data was statistically analyzed using One-way ANOVA with Turkey's multiple comparison test (Post hoc).

Figure 2 shows the distance covered in the different experimental groups which are recorded as: $41.71 \pm 3.99$; $60.88 \pm 8.47 ; 69.25 \pm 7.29$ and $85.50 \pm 8.46 / 5 \mathrm{~min}$ for mice fed control, cooked, uncooked beans and serotonin precursor diets respectively. The distance covered for mice fed with cooked and uncooked beans diets during bean walking was significantly higher $(\mathrm{P}<0.05)$ compared to control. However, the distance covered for the serotonin precursor fed mice was also significantly higher $(\mathrm{p}<0.01)$ compared to the control group. The latency of fall of the different experimental groups are as follows: $7.36 \pm 10.56 ; 11.83 \pm 1.27 ; 13.9 \pm 2.59$ and $15.37 \pm 3.48$ seconds for mice fed control, cooked, uncooked beans and serotonin precursor diets respectively. The latency of fall was longer for the cooked, uncooked beans and serotonin precursor diets fed mice compared to control at $\mathrm{p}<0.05$ (Figure 3).

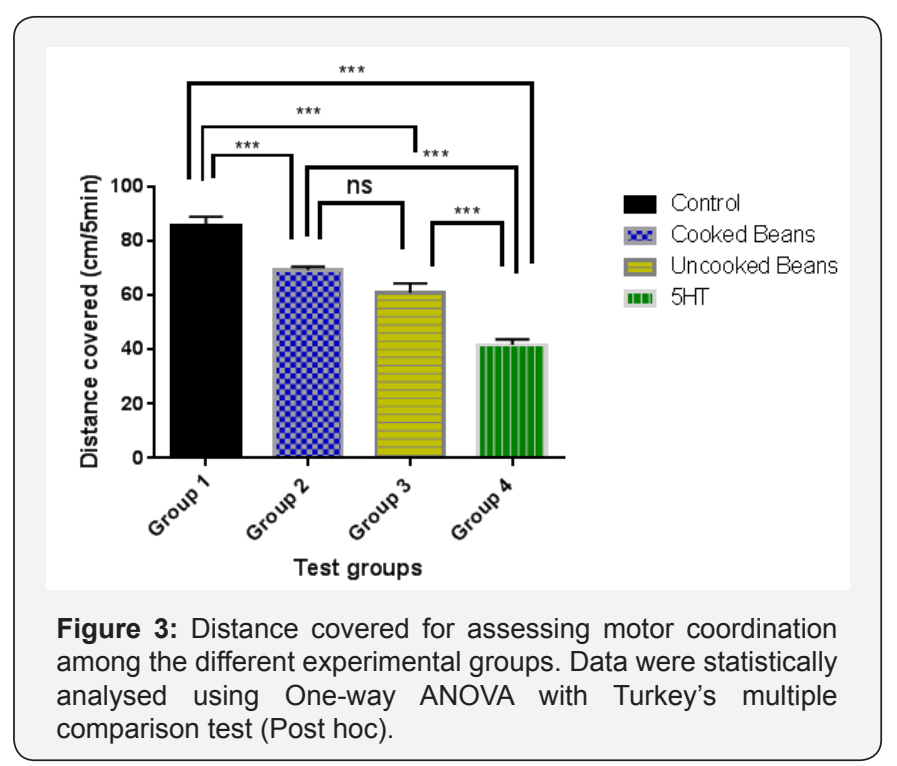

The arm strength test for the different experimental groups was recorded as $34.37 \pm 5.83 ; 37.0 \pm 5.90 ; 36.52 \pm 7.05$ and 36.65 \pm 4.47 (Trial 1) for mice fed with control, cooked, uncooked beans and serotonin precursor diets respectively. The arm strength values for trial 2 are: $26.44 \pm 4.36$; $36.17 \pm 7.08$; $26.52 \pm 7.83$ and $35.83 \pm 4.71$ for mice fed with control, cooked, uncooked beans and serotonin precursor diets. In both trials, there was no significant difference. This is shown in Figure 4.

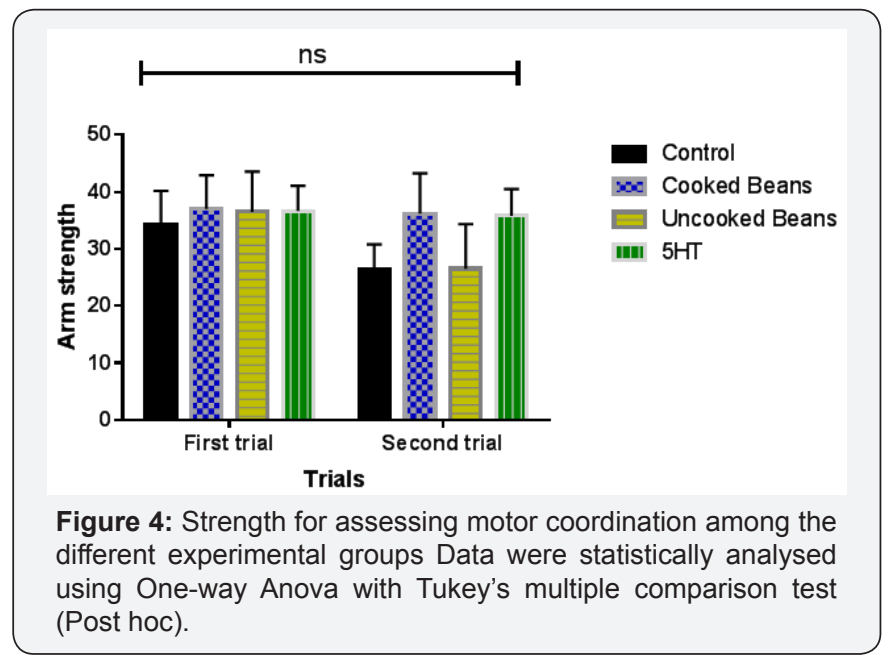

\section{Mean Daily Food Intake}

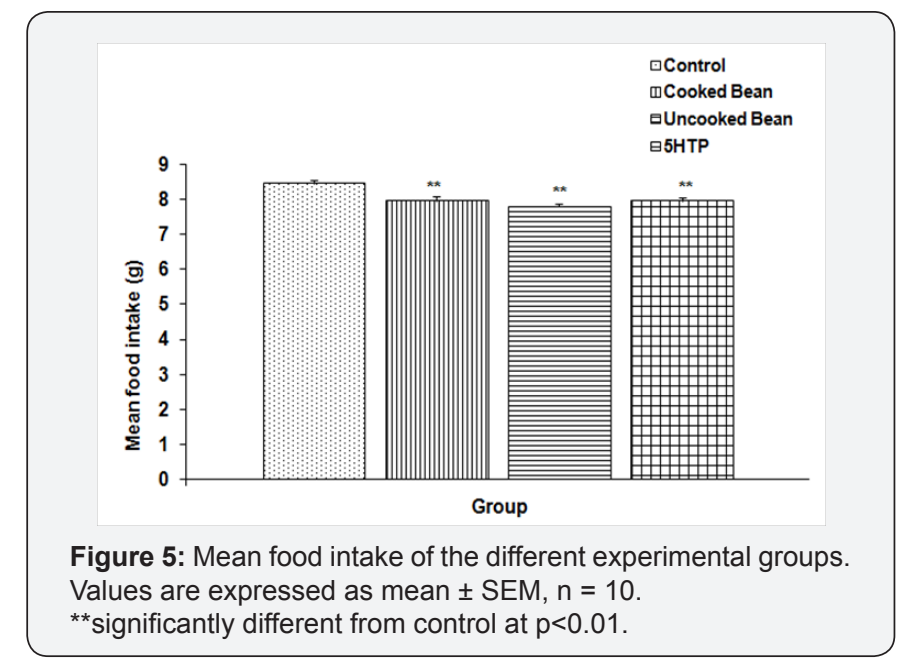

Figure 5 shows the mean daily food intake values of the four experimental groups were $8.44 \pm 0.5$ (control), $7.9 \pm 0.09$ (cooked), 7.79 \pm 0.17 (uncooked), and $7.95 \pm 0.08$ grams (serotonin precursor).The mean food intake was significantly lower in the group of mice fed, cooked, uncooked and serotonin precursor diets compared to control $(\mathrm{p}<0.01)$.

\section{Discussion}

The beam apparatus has been used to study the effects of drugs on motor or neuromuscular coordination [9], cerebella function [10] and motor learning [11]. The task involved the ability of the mice to learned to maneuver their way and stay on the beam balance for as long as possible. The latency of fall in the groups of mice treated with the beans diet was significantly longer when compared to their control for the period of training 
on the beam apparatus. This means that the animals in the test groups learned better to stay on the beam compared to their control. The trend was similar in the serotonin precursor group (5-HTP).Thus; this implies that motor coordination and motor learning were significantly enhanced following administration of the beans diet. So, beans diet may enhance the cerebellum that is involved in the performance of learned motor task $[10,11]$. Furthermore, the decrease in the frequency of foot slips and longer distance covered also indicates a higher level of maneuverability in the beam, thus indicating better motor coordination, since the cerebellum is involved in learned adjustments that make motor coordination easier when a given task is performed over and over [12]. The result is in consonance with earlier work carried out by [13].

The mean daily food intake was significantly lower in the mice treated with the beans and serotonin precursor (5-HTP) diets when compared with the control. Food and water intake are controlled by the lateral hypothalamic nucleus which is the hunger center and the ventromedial hypothalamic nucleus which is the satiety center and so, when the lateral hypothalamic nucleus center is stimulated the animal eats and drinks voraciously. On the other hand, when the ventromedial hypothalamic nucleus center is stimulated, the animals stop feeding. It likely therefore, that beans diet may have a stimulatory effect on the ventromedial hypothalamic nucleus thus causing satiety, thereby decreasing food intake. This result is in consonance with previous research which shows that serotonin modulates dopamine action, thereby decreasing appetite [14].

\section{Limitation of the Study}

The research was not sponsored by any corporate organization or film but by myself single handedly, hence finance was a major constrain.

\section{Conclusion}

In conclusion, long term consumption of beans diet improves motor coordination but reduce food intake. If these results are applicable to man beans consumption could be used in the control and management of ataxia, the animal model of Parkinson's disease, combat hunger and regulate body weight in obese persons.

\section{Acknowledgement}

We acknowledged Pa and Mrs. BA Aduema, Mr. Iwasam Joshua, Dr. Nmaju and Associate Prof. AA Nwankwo for their priceless support.

\section{References}

1. Henshaw DR, Attia E, Bhargava M, Hannafin JA (2008) Competitiveness of cowpea based processed products. Journal of Orthopaedic Research 24(3): 481-490.

2. Sigh AK and Rachie E (1997) Epidemiology of black eye beans mosaic virus. Indian Journal of Virology 13(2): 143-145.

3. Kay DE (1997) Food legumes. Tropical Products Institute, Ministry of Overseas Development pp: 435.

4. Oyenuga VA (1968) Nigeria's foods and foodstuffs. Ibadan, University.

5. Brunton LB, Lazio JS, Parker KL (2005) Therapeutics. The Pharmacological Basis of Therapeutics (607-629).

6. Messman T (2005) Psychiatric drugs: Chemical warfare on humans: Interview with Robert Whitaker.

7. Feldman JM, Lee E (1985) Serotonin content of foods: Effect on urinary excretion of 5-hydroxylindole acetic acid. American Journal of Clinical Nutrition 42(4): 639-643.

8. Mosienko V, Bert B, Beis D, Mather S, Fink H, et al. (2012) Exaggerated aggression and anxiety in mice deficient in serotonin. Translational Psychiatry 2(5): 122-124.

9. Hymson DL, Hydes MD (1982) Evidence that ethanol- induced impairment of Rod-rod performance is not mediated by opioid mechanisms. Progress of Neuro-Psychopharmacology and Biological Psychiatry 6(2): 159-165.

10. Caston J, Delvulder B, Jouen F, Lalonde (1998) Role of an enriched environment on the restoration of behavioural deficits in Lurcher mutant mice. Developmental Psychobiology 35(4): 291-303.

11. Hyde LA, Crnic LS, Pollock A, Bickford PC (2001) Motor learning in Ts65Dn mice, a model for Down syndrome. Developmental Psychobiology 38(1): 33-45.

12. Ganong WF, Barrette KE, Berman SM, Boitano S, Brooks Hl (2010) Ganong's Review on Medical Physiology 76-230.

13. Aduema W, Ama AK, Izuwanne DI (2016) Effect of cooked beans (Vignaunguiculata) on motor coordination and social behavior in Swiss white mice. Intern J Curr Multidisci Studies 2(12): 531-535.

14. Stahl SM, Mignon L, Meyer JM (2009) Which comes first: atypical treatment or cardio metabolic risk. Acta Psychiatrica Scandinavia 119(3): 171-179.

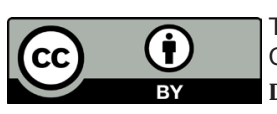

This work is licensed under Creative Commons Attribution 4.0 License

DOI:_10.19080/PBSIJ.2018.08.555729 